\title{
Biopolítica e direitos humanos: uma relação revisitada guiada pelo cortejo da ajuda humanitária
}

\author{
Biopolitics and human rights: a relationship revisited oriented by the \\ courtship of humanitarian help
}

\section{Daniel Arruda Nascimento}

Doutor em Filosofia pela Universidade Estadual de Campinas (Unicamp), professor do Programa de Pós-Graduação em Ética e Epistemologia da Universidade Federal do Piauí (UFPI) e da Universidade Federal Fluminense (UFF), Macaé, RJ -Brasil, e-mail: danielnascimento@voila.fr

\section{Resumo}

Com o escopo de revisitar a relação entre biopolítica e direitos humanos, as linhas que se seguem se dedicam ao diálogo que Giorgio Agamben estabelece com Hannah Arendt. The origens of totalitarianism e The human condition, publicados respectivamente em 1951 e 1958, e Homo sacer: il potere sovrano e la nuda vita e Mezzi senza fine: note sulla politica, publicados em 1995 e 1996, serão as referências mais proeminentes. O diálogo será, todavia, orientado pelo cortejo da ajuda humanitária. Devemos levar a sério as hipóteses do filósofo italiano a esse respeito. Por um lado, o humanitário surge no nosso século purificado de todo comprometimento político, contribuindo para consolidar a compreensão da vida como mera vida, vida biológica, simples fato de ser vivente. Por outro lado, aferrando-se 
contraditoriamente na visão da "vida nua" como aquela desprovida de direitos, podemos observar que a ajuda humanitária substitui o reconhecimento, a atribuição e a garantia de direitos. A distribuição de cestas básicas e remédios adia sempre mais o gesto de reconhecimento da igualdade, a justa atribuição de direitos e a garantia de oportunidades para o exercício de direitos, levando-nos ao ponto de não mais evitar as suspeitas de que uma secreta solidariedade, celebrada entre os organismos internacionais de ajuda humanitária e as forças que deveriam combater, embala os sonhos contemporâneos.

Palavras-chave: Biopolítica. Direitos humanos. Ajuda humanitária.

\section{Abstract}

With the intention of considering the relation between biopolitics and human rights, the following lines are devoted to the dialogue that Giorgio Agamben establishes with Hannah Arendt. The origins of totalitarianism and The human condition, published respectively in 1951 and 1958, and Homo sacer: il potere sovrano e la nuda vita and Mezzi senza fine: note sulla politica, published in 1995 and 1996, shall be our more prominent references. The dialogue will be, however, oriented by the courtship of humanitarian help. We should take seriously the hypothesis of the Italian philosopher here upon. On one side, the humanitarian sense emerges in our century purified of every political commitment, contributing to consolidate the comprehension of life as mere life, as biological life, as simple fact of being alive. On the other side, holding paradoxically the vision of bare life as the one dismissed of rights, we could observe that the humanitarian aid replaces the recognition, the assignment and the guarantees of rights. The distribution of food and medicine delays always more the gesture of recognition of equality, the fair assignment of rights and the guarantees of opportunities in order to allow the exercise of those rights. It takes us to the point where we can't avoid anymore the suspicions that a secret solidarity, renewed between the international organizations of humanitarian aid and the forces that they must confront, nourishes the contemporary dreams.

Keywords: Biopolitics. Human rights. Humanitarian help.

A título de apanhado histórico, podemos dizer que a modernidade trouxe consigo uma série de elementos que contribuíram para que 
os direitos humanos fossem, desde o início de sua concepção, associados aos direitos do sujeito. A valorização do homem como homem, a configuração do sujeito como sede da razão e critério da verdade, a constituição de um núcleo duro subjetivo capaz de assimilar direitos e oponível ao poder soberano são alguns desses elementos que se apresentaram progressivamente. $\mathrm{O}$ momento era então propício para que a filiação dos direitos humanos aos direitos do indivíduo natural redundasse na priorização de determinados sentidos de sujeito e na consolidação do individualismo endêmico. Talvez essa tenha sido a única via possível a fim de que fossem reconhecidos os direitos humanos, a fim de que os direitos humanos galgassem o posto de destaque a que estavam direcionados e que positivamente alcançaram. Mas o leitor do século XXI oscila entre a admiração sem reservas ao cânone dos direitos humanos e a desconfiança deles. O leitor do século XXI é aquele que não sabe se dar credibilidade ao discurso de defesa dos direitos humanos é tarefa digna de si: uma dúvida potencializada na medida em que ele pode lançar um olhar sensibilizado e prudente ao que acontece a seu redor. Com arguta observação, diz um de nossos companheiros de viagem:

o fosso que separa a proclamação formal e a negação real dos direitos humanos em muitas de nossas sociedades nos leva a analisar, criticamente, quais são os dispositivos pelos quais os direitos humanos conseguem coexistir e até legitimar a desigualdade social, a injustiça estrutural e inclusive atos de violência e de guerra (RUIZ, 2010, p. 195).

Com efeito,

o século $\mathrm{XX}$ assistiu ao conflito de um movimento contraditório nas várias encenações do discurso público dos direitos humanos. A efetivação dos direitos em políticas institucionais e nas normas do direito internacional caminhou conjuntamente ao uso indiscriminado da violência por parte dos estados (TELES, 2010, p. 287).

Ficamos espantados com o fato de que podem os direitos humanos e a retórica que os envolve operar no sentido inverso ao que era de se esperar desde a sua protuberância original. 
Em uma conferência que traz o provocativo título Barbárie: manual do usuário, proferida em 1994, Eric Hobsbawm, o historiador egípcio que dispensa apresentações, demonstra que a ascensão e a queda do moderno projeto iluminista têm estreita relação com o estabelecimento dos direitos humanos e com o incremento de sua violação e da barbárie em geral. Se a vigência de uma declaração formal de direitos humanos pode ser associada ao desenvolvimento do projeto iluminista, o fracasso desse projeto implica no desamparo da proteção ao homem pelo simples fato de ser homem ou pelo fato de ter se tornado um sujeito. $\mathrm{O}$ apelo ao racional e à consagração de determinados valores perde o seu vigor diante do aumento da barbárie. E tudo indica que o que vemos produzir-se como barbárie produzirá mais barbárie. Assim Eric Hobsbawm se refere ao seu tempo:

Após cerca de 150 anos de declínio secular, a barbárie esteve em crescimento durante a maior parte do século $\mathrm{XX}$, e não há nenhum indício de que esse crescimento esteja no fim. Nesse contexto, entendo que "barbárie" signifique duas coisas. Primeiro, a ruptura e o colapso dos sistemas de regras e comportamento moral pelos quais todas as sociedades controlam as relações entre seus membros e, em menor extensão, entre seus membros e os de outras sociedades. Em segundo lugar, ou seja, mais especificamente, a reversão do que poderíamos chamar de projeto do Iluminismo do século XVIII, a saber, o estabelecimento de um sistema universal de tais regras e normas de comportamento moral, corporificado nas instituições dos Estados e dedicado ao progresso racional da humanidade: à Vida, Liberdade e Busca da Felicidade, à Igualdade, Liberdade e Fraternidade, ou seja lá o que for. As duas coisas estão agora acontecendo e reforçam seus respectivos efeitos negativos em nossas vidas. A relação entre meu tema e a questão dos direitos humanos deve, portanto, ser óbvia (HOBSBAWM, 1998, p. 268-269).

\section{Direitos humanos e politização da vida}

Quem quiser compreender a fundo a condição do homem contemporâneo no que se refere ao fato de ser o homem o destinatário natural dos direitos concedidos por razão mesma de ser homem, precisa

Rev. Filos., Aurora, Curitiba, v. 25, n. 37, p. 131-150, jul./dez. 2013 
percorrer as páginas de Hannah Arendt publicadas na metade do século XX. Origens do totalitarismo é um livro seminal. Muito além de um livro que recolhe dados históricos e os analisa com precisão, ele é um livro maravilhoso em seu aspecto filosófico e fecundo no que diz respeito à possibilidade de fazer refletir. É sempre novamente impressionante ver como Hannah Arendt, mesmo que seja bastante sensível à necessidade de se reconhecer e garantir direitos aos homens, seja capaz de confrontar o seu texto com a retórica inopinada dos direitos humanos. Bem conhecida é a dedicação de seu texto à apresentação do problema dos refugiados e dos apátridas e, em um grau superior, da relação de alternância decadente entre Estado-Nação e direitos do homem. A tentativa de resolver os problemas políticos europeus fazendo estabelecer Estados-Nação com populações heterogêneas e sem fixação ao território e introduzir tratados de minorias fez surgir minorias que se sentiam arbitrariamente reduzidas à situação de servidão. Desde o fim do século XIX até o primeiro quarto do século XX, a eclosão de revoluções sociais, entendidas aqui no seu sentido mais genérico, as novas configurações geopolíticas e os programas de desnacionalização e desnaturalização fizeram surgir povos que não pertenciam a qualquer Estado. Os refugiados, em fuga de seus países de origem, teoricamente protegidos pelo direito de asilo, foram unidos aos apátridas, gente sem pátria, sem qualquer proteção constitucional. As declarações de direitos universais que se fizeram proclamar em nome do homem viram seus homens diluírem-se em membros de um povo, "toda a questão dos direitos humanos foi associada à questão da emancipação nacional" (ARENDT, 1989, p. 325). Os direitos humanos supostamente inalienáveis mostraram-se inexequíveis "sempre que surgiam pessoas que não eram cidadãos de algum Estado soberano" (ARENDT, 1989, p. 327). Posteriormente, "a perda dos direitos nacionais levou à perda dos direitos humanos" (ARENDT, 1989, p. 333).

Notemos que as análises de Hannah Arendt não se restringem às transformações decorrentes dos regimes totalitários. As preocupações da autora, expressas em seu texto, levam-nos além, levam-nos a compreender a situação desse homem destinatário dos direitos humanos acompanhado pelo seu devir histórico moderno. Mesmo antes do 
advento totalitário, "só o espírito de solidariedade podia impedir o exercício por algum governo de todo o poder potencialmente soberano" (ARENDT, 1989, p. 312). Quase não havia país europeu que não tivesse, entre as duas grandes guerras, aprovado alguma legislação que permitisse a rejeição e a eliminação de um elevado número de seus habitantes se a alternativa se mostrasse apropriada ao seu governo.

Nenhum paradoxo da política contemporânea é tão dolorosamente irônico como a discrepância entre os esforços dos idealistas bem-intencionados, que persistiam teimosamente em considerar 'inalienáveis' os direitos desfrutados pelos cidadãos dos países civilizados, e a situação dos seres humanos sem direito algum (ARENDT, 1989, p. 312).

O que fez o evento totalitário foi demonstrar que a afirmação dos direitos humanos inalienáveis revelavam hipocrisia e covardia (ARENDT, 1989, p. 302). Hipocrisia e covardia que se prolongam no tempo, retrocedendo, em alguma medida, ao momento de instituição dos direitos do homem e se estendendo, como transes inesgotáveis, até atingir os nossos dias.

Estando já longe os horrores das grandes guerras e passada uma insustentável euforia política posterior, chegamos a um momento em que se torna cada vez mais relevante repensar o estatuto dos direitos do homem. O suposto clima político brando, ameno, de calmaria, no qual estamos inseridos, no qual toda crise é considerada apenas como se fora isolada no seu aspecto econômico, dissimula tanto a urgência de se reconhecer que estamos muito aquém da real proteção universal quanto a iminência de que grandes eventos possam abalar, em um futuro próximo, nossa confiança no processo civilizatório. Entre aqueles professores universitários que, cientes das responsabilidades que estão nas entranhas de suas funções, têm a intenção de atualizar o pensamento de Hannah Arendt, articulando-o com as contribuições inobliteráveis de Michel Foucault, encontramos Giorgio Agamben. O incentivo às reflexões trazido com a publicação, em 1995, de Homo sacer: il potere sovrano e la nuda vita não pode ser desprezado. Munido do melhor espírito filosófico, suas páginas nos levam a atingir aquela intensidade do

Rev. Filos., Aurora, Curitiba, v. 25, n. 37, p. 131-150, jul./dez. 2013 
pensamento que nos desestabiliza mas provoca o desejo de rearrumar, o desafio de pensar de novo.

Em lugar diverso, quando ainda se tratava de acompanhar e mapear o percurso de Giorgio Agamben até então realizado, precisei deter-me por um momento para considerar a articulação teórica envolvendo biopolítica e direitos humanos. Estávamos em meio à tentativa de compreender certas estruturas de exceção e o seu alcance. Lá, procurei demonstrar que, assumida determinada linha de argumentação, sob o olhar do filósofo italiano: o anúncio dos direitos humanos por meio de declarações universais correspondia à inscrição da vida nos cálculos do poder estatal; as rupturas da relação de pertencimento entre nascimento e nação levavam ao colapso o sistema de proteções; a inclusão do homem na esfera dos direitos somente se dava na forma da exclusão (NASCIMENTO, 2012, p. 179-187). Na época, já estava suficientemente claro para mim que algumas frases ditas no calor da hora - tal como aquela com a qual termino o capítulo dedicado ao tema: "urge reconhecer que a simples inscrição da vida natural nos tratados internacionais seria o elo de um processo de dominação que recebeu o nome de biopolítica e que ainda hoje atua com uma força arrasadora" (NASCIMENTO, 2012, p. 187) -, se tomadas sem a devida contextualização e como se fossem apenas frases de efeito, podem parecer abusivas, desproporcionais ou desinformadas. Qualquer grau de ponderação sugere que consideremos os avanços em termos de proteção e de auxílio às vítimas da violência e do abandono nos últimos dois séculos. Não é possível ignorar que esforços múltiplos, nos campos político, jurídico e institucional, esforços oriundos do poder constituído, da sociedade civil organizada ou de movimentos sociais, tenham como horizonte a efetivação de tal proteção e auxílio, assim como não é possível menosprezar que o projeto iluminista, embora hoje inteiramente fracassado, tenha legado ao nosso século um conjunto de valores que serve de último anteparo a impedir "uma queda acelerada nas trevas" (HOBSBAWM, 1998, p. 269). Sem a confiança de outrora na razão e sem a certeza dos fundamentos que os legitimariam, alguns valores universais são, apesar de tudo, honrados por nós como último recurso contra a barbárie em larga escala. Esse é evidentemente um dos fatores que 
garantem a positivação dos valores pelos Estados, a concepção de políticas públicas afirmativas, o surgimento de organizações não governamentais e de movimentos sociais difusos tendo como mote o respeito aos direitos humanos.

Todavia, para um leitor do século XXI preocupado com os destinos do pensamento político contemporâneo, não é absurdo pensar que tenham as declarações de direitos humanos adquirido duas faces diametralmente opostas, assim como, segundo o filósofo italiano, o personagem Frenhofer, do escritor francês Honoré de Balzac, o qual protagoniza a moderna duplicação geométrica da arte e a distinção entre artista e espectador, tornando-se mais de um. Frenhofer, personagem de Le chef-d'oeuvre inconnu, conto de 1831 integrado a La comédie humaine, teria duas faces:

uma face voltada para o artista é a realidade vivente na qual ele lê a sua promessa de felicidade; mas a outra face, aquela voltada para o espectador, é um conjunto de elementos sem vida que pode somente refletir-se na imagem que lhe restitui o juízo estético (AGAMBEN, 1994, p. 23).

Com o pesar das vítimas de violência que esperam por uma redenção prometida, tememos que as declarações dos direitos do homem, adquirindo duas faces diametralmente opostas, tenham uma delas voltada para a contemplação de si e outra voltada para as vítimas não amparadas. Pior, tememos que as declarações dos direitos do homem sobrevivam apenas na sua função estética. Recuperando uma antiga intuição arendtiana, lembramos que os direitos humanos existem apenas quando não são necessários.

Em um texto de 1996, publicado no ano seguinte ao livro que inaugura o projeto filosófico que lhe deu notoriedade, Homo sacer: il potere sovrano e la nuda vita, Agamben chama a atenção do seu leitor para a "ambivalência do conflito biopolítico em curso, no qual a liberdade e a felicidade dos homens se jogam sobre o mesmo terreno - a vida nua - que assinala a sua subserviência ao poder" (AGAMBEN, 2010, p. 402). O nosso tempo é aquele em que a proeminência do cálculo e da gestão sobre a vida abrange todos os aspectos relacionados 
à vida do homem, a sua liberdade, a sua felicidade e a possibilidade de sua destruição. Algo muito natural para um grau de evolução da humanidade que atingiu pela primeira vez, com o desenvolvimento tecnológico e o incrível aumento do poder de destruição, a real possibilidade de extinção de todo o planeta, por meio da decisão, por exemplo, de um grupo de homens que representem um governo qualquer (ARENDT, 2011, p. 17-18).

\section{0 cortejo da ajuda humanitária}

Disso tudo decorre a complexidade que envolve a classificação das ações humanitárias. Acompanhemos o exame de Giorgio Agamben. Por um lado, o humanitário surge entre nós purificado de todo comprometimento político, se político for compreendido como o serviço de organização da cidade, ou da comunidade dos vivos.

A separação entre humanitário e político, que estamos hoje vivendo, é a fase extrema do descolamento entre os direitos do homem e os direitos do cidadão. As organizações humanitárias, que se unem hoje em medida crescente aos organismos supranacionais, não podem, entretanto, em última análise, mais do que compreender a vida humana na figura da vida nua ou da vida sacra, e mantêm por isto mesmo a contragosto uma secreta solidariedade com as forças que deveriam combater (AGAMBEN, 1995, p. 147-148).

Excluindo-se do âmbito político que, se é o espaço do discurso e da ação, é também o do jogo, da aparência, da dissimulação e da enganação, as ajudas humanitárias contribuem para consolidar a compreensão da vida enquanto "vida nua", mera vida, simples fato de ser vivente. Por outro lado, aferrando-se contraditoriamente na visão da vida nua como aquela desprovida de direitos, vemos que a ajuda humanitária substitui o reconhecimento, a atribuição e a garantia de direitos. A distribuição de cestas básicas e remédios adia sempre mais o gesto de reconhecimento da igualdade, a justa atribuição de direitos e a garantia de oportunidades para o exercício de direitos. 
O sonho que embala a secreta solidariedade entre os organismos internacionais de ajuda humanitária e as forças que deveriam combater, ainda que se apodere do imaginário dos que ajudam sem evitar o gosto amargo da boca, corresponde à alegria ingênua do fotógrafo humanitário ao encontrar uma cena digna de pena, a oportunidade de uma fotografia que cause lástima e comova o doador.

Os "olhos suplicantes" do menino ruandês, cuja fotografia se desejaria exibir para obter dinheiro, mas que "está agora se tornando difícil encontrar vivo", são o índice talvez mais significativo da vida nua no nosso tempo, da qual as organizações humanitárias têm necessidade em proporção exatamente simétrica ao poder estatal (AGAMBEN, 1995, p. 148).

Mais doloroso para quem queira se aproximar da relação entre os direitos humanos e as ajudas humanitárias é perceber que as ajudas humanitárias mantêm as vítimas na condição de vítimas. E que as justificativas para evitar qualquer passo além da ajuda humanitária emergencial e passageira só podem ser compreendidas pelos que não estão na condição de vítimas. Aos vitimados, tais justificativas não são compreensíveis e soam como subterfúgio para preservar processos históricos de dominação.

Devemos levar a sério a hipótese de que a ajuda humanitária venha em substituição ao reconhecimento, à atribuição e à garantia de direitos. Ela deve ser examinada com seriedade não somente porque os organismos que sustentam a ajuda humanitária são na sua maioria sustentados, por sua vez, por empresas e governos acostumados à prática predatória, ou porque tais atividades aliviem uma espécie de sentimento de culpa coletivo alimentado, por sua vez, pelo irrefreável consumo exclusivista do cidadão médio. Ou mesmo porque, do ponto de vista das vítimas mantidas vítimas, soem ridículos os artigos da Declaração Universal dos Direitos Humanos de 1948, tais como aqueles nos quais são enunciados o direito ao igual tratamento e proteção (artigos I, II e VII), o direito ao acesso aos órgãos de justiça (artigos VIII e X), o direito ao acesso aos serviços públicos (artigo XXI), o direito à segurança (artigo XXII), ao trabalho e à remuneração justa (artigos XXIII e XXV), à educação (artigo XXVI) e à cultura (artigo XXVII), na 
medida em que o mundo vivido encontra-se rasgado pela desigualdade econômica e pelo desigual poder de compra ${ }^{1}$. Devemos levar a sério a hipótese aventada porque, enquanto boa parte dos recursos mundiais são dotados às atividades de ajuda humanitária, deixamos para segunda ordem as consequências de uma detida consideração sobre o que significa justiça, as implicações da redistribuição de riquezas e da maior participação política nas decisões comunitárias.

O que agora é universalizado e estendido até o limite da condição do cidadão fora observado na situação histórica do refugiado, um problema que se arrasta por quase cem anos sem encontrar solução. Em um trecho publicado em 1996, parte integrante de um capítulo com o sugestivo título de Al di là dei diritti dell'uomo, aludindo ao fiasco dos comitês internacionais para os refugiados, Agamben sublinha que:

[...] toda vez que os refugiados não representam mais casos individuais, mas um fenômeno de massa [...] tanto estas organizações quanto os Estados singulares, apesar das solenes evocações dos direitos inalienáveis do homem, demonstram-se absolutamente incapazes não só de resolver o problema, mas também simplesmente de enfrentá-lo de modo adequado. A inteira questão foi, assim, transferida para as mãos da polícia e das organizações humanitárias (AGAMBEN, 1996, p. 23).

O que aparenta ser proteção da vida pode não ser real proteção da vida. Em uma situação de completa privação de direitos, o direito à vida não precisa ser frontalmente ameaçado para que a vida seja ameaçada. Esse é o argumento mobilizado por Hannah Arendt: é possível criar uma condição de completa privação de direitos antes que o direito à vida seja ameaçado, o que equivale, em última instância, à privação das condições nas quais a vida se sustenta. Trata-se evidentemente da questão da eficiência de uma declaração formal dos direitos. Um exemplo dado pela autora demonstra que a proteção da liberdade pode não ter qualquer serventia para a conservação da liberdade, no

1 "Deus não está morto, ele se tornou dinheiro", ressalta Giorgio Agamben em uma recente entrevista a Giuseppe Savà, publicada no site Ragusa News, em 16 de agosto de 2012, referindo-se à hegemonia do argumento econômico atual. Disponível em: <http://www.ragusanews.com/articolo/28021/>. Acesso em: 19 set. 2012. 
que se refere aos que estão fora do âmbito da legalidade ou do reconhecimento de direitos. Ela escreve:

O mesmo se aplica, com certa ironia, em relação ao direito de liberdade, que é, às vezes, tido como a própria essência dos direitos humanos. Não há dúvida de que os que estão fora do âmbito da lei podem ter mais liberdade de movimento do que um criminoso legalmente encarcerado, ou de que gozam de mais liberdade de opinião nos campos de internação dos países democráticos ao que gozariam sob qualquer regime despótico comum, para não falar de países totalitários. Mas nem a sua segurança física - como o fato de serem alimentados por alguma instituição beneficente estatal ou privada - nem a liberdade de opinião alteram a sua situação de privação de direitos. O prolongamento de suas vidas é devido à caridade e não ao direito, pois não existe lei que possa forçar as nações a alimentá-los; a sua liberdade de movimentos, se a têm, não lhes dá nenhum direito à residência, do qual até o criminoso encarcerado desfruta naturalmente; e a sua liberdade de opinião é uma liberdade fútil, pois nada do que pensam têm qualquer importância (ARENDT, 1989, p. 329-330).

Se dermos a devida atenção ao argumento apresentado, chegaremos à conclusão de que a tutela humanitária bem pode ser um dispositivo ardiloso para a real negativa no que diz respeito ao reconhecimento e à exigibilidade dos direitos. Este é um ponto crucial para Hannah Arendt: "a privação fundamental dos direitos humanos manifesta-se, primeiro e acima de tudo, na privação de um lugar no mundo que torne a opinião significativa e a ação eficaz" (ARENDT, 1989, p. 330).

Pouco adiante, no mesmo capítulo, vemos Hannah Arendt salientar quão paradoxal foi a vinculação dos direitos humanos à noção de natureza humana ${ }^{2}$. Se os direitos humanos foram, mesmo que apenas inicialmente ou por comprometimentos secundários, vinculados à existência de uma natureza do homem, no momento em que o homem do século XX se emancipou da natureza, restou claro que nenhuma na-

2 "Começa a se firmar, com Grotius e Hobbes, a teoria jusnaturalista dos direitos do homem, cuja sede e fundamentação seria a própria natureza racional e afetiva - a humanitas do homo humanus. Daí porque, sobretudo desde o século XVII, pode-se constatar a transição, perfeitamente justificável em termos de racionalidade, entre direitos naturais e direitos humanos" (GIACOIA Jr., 2008, p. 267-268).

Rev. Filos., Aurora, Curitiba, v. 25, n. 37, p. 131-150, jul./dez. 2013 
tureza podia conceder direitos. O conceito de direitos humanos fundado em uma suposta natureza humana desmoronou no mesmo instante em que as vítimas que historicamente se apresentaram haviam perdido todo o pertencimento a uma comunidade política, todas as outras qualidades com exceção daquela de serem ainda humanas. "O mundo não viu nada de sagrado na abstrata nudez de ser unicamente humano [...] a nudez abstrata de serem unicamente humanos era o maior risco que corriam" (ARENDT, 1989, p. 333). Abandonados pela comunidade política, essas vítimas perderam qualquer acesso aos direitos, sejam eles humanos, sejam eles civis, sendo entregues à própria nudez, sendo expostas à violência e à morte. "O paradoxo da perda dos direitos humanos é que essa perda coincide com o instante em que a pessoa se torna um ser humano em geral" (ARENDT, 1989, p. 335-336).

Feitas essas considerações, conhecendo as obras de Arendt e Agamben, como não pensar que a primeira, de algum modo, antecipe as teses do segundo ou que o segundo tenha se deixado influenciar visceralmente pela primeira ${ }^{3}$ ? No que diz respeito aos limites dos direitos humanos, ambos parecem se preocupar com a absoluta nudez do humano, com a vida humana considerada unicamente no seu elemento biológico, o que se converterá em um conceito para o filósofo italiano: o conceito de vida nua.

Hannah Arendt estava ainda consciente de que toda essa discussão nos remetia a outra atinente aos modernos processos de animalização do homem. A nudez abstrata de serem unicamente humanos gerava para seus representantes o receio de que pudessem, em um futuro iminente, serem considerados animais, e não mais humanos (ARENDT, 1989, p. 333). Os homens que não podem mais viver em um mundo comum, partilhar de uma comunidade política construída, comungar de direitos comuns, correm o sério risco de retroceder ao

3 Uma cordial carta do estudante Giorgio Agamben, escrita em Roma no dia 21 de fevereiro de 1970 e endereçada à Sra. Arendt revela sua admiração e sua filiação: "eu sou um jovem escritor e ensaísta para quem descobrir seus livros no ano passado representou uma experiência decisiva. Permita-me expressar aqui minha gratidão a você e, em nome daqueles que, junto comigo, na brecha entre o passado e o futuro, sentem toda a urgência em trabalhar na direção apontada por você?" (Disponível em: <workwithoutdread.blogspot.com.br>. Acesso em: 22 abr. 2012).

Rev. Filos., Aurora, Curitiba, v. 25, n. 37, p. 131-150, jul./dez. 2013 
estado de selvageria, de retroceder ao estado de natureza (ARENDT, 1989, p. 334). Estaríamos diante, então, de um retrocesso do processo civilizatório ${ }^{4}$.

Em L'aperto: l'uomo e l'animale, publicado em 2002, Agamben havia procurado demonstrar que tanto a produção do humano quanto a moderna animalização do homem são resultados de uma mesma máquina antropológica que não cessa de definir e adiar a definição do que seja o humano (AGAMBEN, 2002, p. 43). O filósofo havia salientado que, apesar da imperiosa necessidade de produção do homem pelo Ocidente, a sua animalização constitui um caminho sem volta da máquina antropológica instalada em nossa cultura, a outra face da política centrada nos cálculos sobre a vida, a outra face da assim denominada biopolítica (AGAMBEN, 2002, p. 80). Em La potenza del pensiero: saggi e conferenze, publicado em 2005, um livro que reúne ensaios e conferências escritos principalmente nas décadas de 80 e 90, mas que traz em suas últimas páginas um importante texto de 2004, intitulado L'opera dell'uomo, Agamben pretende, recorrendo à formação aristotélica do conceito de vida dividido nas funções nutritiva, sensitiva e prático-racional, e na distinção entre potência e ato, demonstrar que o político, como obra do homem, define-se sobretudo na exclusão do fato de ser o homem um mero vivente (AGAMBEN, 2010, p. 378). Entretanto, ele acrescenta, com o fim da Primeira Guerra Mundial e com o fim dos cômpitos históricos consignáveis aos Estados-Nação europeus, "na impossibilidade de definir uma nova 'obra do homem', trata-se de assumir agora a própria vida biológica como último e decisivo encargo histórico" (AGAMBEN, 2010, p. 379). A biopolítica rejuvenescida do século $X X$ traz consigo uma política nova, uma política que retorna sobre a vida vegetativa ou animal. Mais uma vez, o que está em jogo é a animalização do homem. Dito isso, como não reputar que a ajuda humanitária, na medida em que, na atualidade, se apresente como o

${ }^{4}$ Celso Lafer está particularmente atento a esse aspecto do pensamento da filósofa alemã: "a experiência histórica dos displaced people levou Hannah Arendt a concluir que a cidadania é o direito a ter direitos, pois a igualdade em dignidade e direito dos seres humanos não é um dado. É um construído da convivência coletiva, que requer 0 acesso a um espaço público comum. Em resumo, é esse acesso ao espaço público - o direito de pertencer a uma comunidade política - que permite a construção de um mundo comum através do processo de asserção dos direitos humanos" (LAFER, 1997, p. 58).

Rev. Filos., Aurora, Curitiba, v. 25, n. 37, p. 131-150, jul./dez. 2013 
estandarte da defesa dos direitos humanos e tome como seu objeto de atividade a vida biológica, acarrete o esquecimento do destino político do homem, abandonando-o ao simples fato de viver, à "vida nua"?

Recordando que Michel Foucault havia definido a diferença entre o biopoder moderno e o poder soberano do antigo Estado com a acomodação de duas expressões simétricas, fazer morrer e deixar viver, no segundo caso, e fazer viver e deixar morrer, no primeiro, Agamben aludirá a uma terceira expressão, que faz aqui as vezes de uma imagem satélite: não mais fazer morrer ou fazer viver, mas fazer sobreviver. A prestação decisiva da biopolítica do nosso século é a produção de uma sobrevivência modulável, na qual se trataria cada vez de distender ao limite as cisões impostas ao homem - cisões, por exemplo, como aquela que separa o homem do animal, ou o humano do não humano (AGAMBEN, 1998, p. 145). O que é sobreviver? - poderíamos perguntar. Sobreviver significa viver apesar de. Sobreviver é estar vivo quando seria mais provável não estar, é viver quando todas as previsões apontariam para o resultado inverso. Essa é a condição do homem contemporâneo? Sobreviver, não é isso que os animais fazem, pelo menos aqueles de pequeno porte, de poucos instrumentos de defesa, no natural e selvagem processo seletivo? Fazer sobreviver implica fazer viver tendo atravessado o risco, fazer viver depois de ter a experiência de vida se tornado manipulável.

Estaria o texto de Hannah Arendt restrito à análise das condições das vítimas que antecederam e foram golpeadas pelo evento totalitário? Estaríamos em condições de garantir que um diagnóstico da época hoje seria otimista no que diz respeito ao retorno dos direitos do homem? Não é o que parece se olharmos as últimas páginas do insuperável livro que recebeu o título de $A$ condição humana, de 1958. Com a vida moderna, após um passageiro momento no qual a atividade da fabricação parecia ter se alastrado por toda relação do homem com o seu mundo, não foi a emancipação do homo faber, mas a do animal laborans, com a ascensão do labor como a mais significativa atividade humana no mundo, que se tornou decisiva. Lemos de Hannah Arendt, em postura conclusiva, que "a era moderna continuou a operar sob a premissa de que a vida, e não o mundo, é o bem supremo do homem" 
(ARENDT, 2004, p. 332) ${ }^{5}$. Onde o labor pode ser compreendido como a atividade correspondente ao metabolismo do corpo humano e de sua conservação, a vitória do animal laborans é também a vitória de uma determinada mentalidade, mediada pela ideia de consumo e pelo cuidado da vida do homem na qualidade de espécie.

Uma precisa análise histórica nos leva a compreender com maior deferência o quadro exposto. Tendo o cristianismo influente invertido a relação de prioridade e permanência entre mundo e vida, uma vez que a relação oriunda dos gregos se dava em outro sentido, o mundo tornou-se complementar e passageiro e a vida tornou-se principal e eterna. Para os gregos, o mundo apresentava-se como algo que estava orientado à permanência e a vida, como algo que deveria acabar. Mais: ao sentir grego não havia razão para considerar a vida no seu aspecto meramente biológico, desvinculado de qualquer acepção política, uma vez que ter vida era bem mais que se manter vivo. Daí porque era comum desprezar uma vida na qual os afazeres cotidianos estavam ligados exclusivamente às cautelas da alimentação da vida; daí porque uma vida composta por feitos admiráveis podia ser mais valiosa do que outra menos expressiva; daí porque o suicídio podia ser visto como um nobre gesto de dar fim a uma vida que não era mais digna de ser vivida; daí porque era plenamente aceitável interromper uma vida que trouxesse um defeito com o seu nascimento. O cristianismo que, historicamente, venceu nos ensinou que o mundo estava destinado a um fim e que a vida, sendo criada e querida por um ser divino e eterno, tinha uma existência sem fim. Esse é o veículo inicial para a consolidação do princípio da sacralidade da vida. A vida passa então a ser o bem supremo. Com a inversão do sentimento moderno, permanecer vivo em quaisquer circunstâncias torna-se um dever, mesmo que a vida seja auferida apenas na qualidade de uma sobrevida (ARENDT,

5 Centrado na vida, tende 0 animal laborans a perder a sua adesão ao mundo: "nada expele 0 indivíduo mais radicalmente para fora do mundo humano e comum que a concentração exclusiva no trabalho, ou seja, na manutenção da vida do organismo e da espécie. No trabalho, ocorre uma profunda perda do mundo na qual o homem concentra-se apenas no fato de estar vivo, preso à repetição do seu metabolismo com a natureza" (ALVES NET0, 2009, p. 188). A palavra trabalho refere-se aqui à atividade do labor, em oposição conceitual à fabricação (work) e à ação (action).

Rev. Filos., Aurora, Curitiba, v. 25, n. 37, p. 131-150, jul./dez. 2013 
2004, p. 327-329). Notemos, ainda, que, mesmo com o ocaso da hegemonia do cristianismo na modernidade, o que vemos não é o enfraquecimento do prestígio do princípio da sacralidade da vida, mas a sua ressignificação ${ }^{6}$. Depois do século XIX, se a noção de imortalidade da alma perde sua força, se o moderno devolve o homem à sua condição de habitante terrestre e à sua vida mortal, o imortal passou a ser apenas o processo vital da espécie humana (ARENDT, 2004, p. 334). Politicamente, se a preocupação com a conservação da vida torna-se para nós o pressuposto de toda atividade humana, se a esfera pública passa a funcionar em favor de uma economia doméstica de subsistência e se o predomínio da administração senhorial determina a invasão do público pelo privado, a extinção da diferença entre as esferas pública e privada tem como consequência a submersão de ambas na assim denominada esfera do social, ambiente propício à reprodução e à multiplicação do animal laborans.

Não é preciso ser filósofo para perceber que o homem não é só algo que precisa se alimentar para viver. Uma música conhecida dos brasileiros tem uma estrofe que se repete com fúria: "a gente não quer só comida"7 . O moderno princípio da sacralidade da vida esvaziou a vida humana de conteúdo. Do interior desse processo de esvaziamento, uma nova torrente biopolítica avançou sobre a vida biológica, fazendo dela o objeto dos cálculos infinitesimais de governo, da manipulação tanto laboratorial quanto demográfica.

Contudo, o lado talvez demasiado tragicômico disso tudo é que o abandono dos que seriam os destinatários dos direitos humanos não é sentido pelos que não são abandonados, na medida em que violações a direitos se tornaram triviais, banais. Como se já não bastasse o fato de os direitos humanos existirem apenas quando não são necessários

6 Não é de se estranhar que o Belmont Report de 1978, relatório de síntese norte-americano que balizou as discussões sobre as questões bioéticas, determinando os princípios básicos do desenvolvimento das ciências biológicas e de sua aplicação na medicina, tenha, com a eleição dos princípios do respeito à pessoa e da beneficência, reconhecido uma vez mais, segundo a maioria dos intérpretes especialistas, a inafastabilidade do respeito, da proteção e da promoção da vida humana (DURAND, 2012, p. 145-154).

7 Música "Comida" (1987), do disco Jesus não tem dentes no país dos banguelas (WEA, 1987), composta por Marcelo Fromer, Arnaldo Antunes e Sérgio Britto, popularizada pelo grupo Titãs. 
ou de estarem ausentes justamente quando seriam mais necessários, na absoluta ausência do efetivo gozo de outros direitos, atados, na sua extensa maioria, à condição da cidadania. Por esse motivo, entre outros, é de bom alvitre escutar uma vez mais o lamento de um historiador da última hora que, apesar de compreender as limitações do projeto iluminista e saber, com Hannah Arendt, que os eventos totalitários vieram até nós no exato período em que a razão esclarecida parecia ter triunfado, reconheceu que a confiança na capacidade humana de evoluir era uma das últimas coisas com as quais ainda poderíamos contar. Nas atuais palavras do egípcio Eric Hobsbawm:

sob tais circunstâncias de desintegração social e política, devemos esperar, em todo caso, um declínio na civilidade e um crescimento na barbárie. Entretanto, o que torna as coisas piores, o que sem dúvida as tornará piores no futuro, é o constante desmantelamento das defesas que a civilização do Iluminismo havia erigido contra a barbárie [...]. O pior é que passamos a nos habituar ao desumano. Aprendemos a tolerar o intolerável (HOBSBAWM, 1998, p. 279).

O projeto iluminista, do ponto de vista da biopolítica, é também cotado pela sua correnteza. E o esmagamento alheio já não nos causa estranhamento, perdemos a capacidade de estar alertas ao que ocorre a nosso redor. Mesmo motivados pela ajuda humanitária aos que ainda são encontrados vivos nos cantões de cidades aglomeradas ou continentes inóspitos, somos, com ampla certeza, os mais indiferentes dentre todos os animais.

\section{Referências}

AGAMBEN, G. L'uomo senza contenuto. Macerata: Quodlibet, 1994.

AGAMBEN, G. Homo sacer: il potere sovrano e la nuda vita. Torino: Einaudi, 1995.

AGAMBEN, G. Mezzi senza fine: note sulla politica. Torino: Bollati Boringhieri, 1996.

Rev. Filos., Aurora, Curitiba, v. 25, n. 37, p. 131-150, jul./dez. 2013 
AGAMBEN, G. Quel che resta di Auschwitz: l'archivio e il testimone. Torino: Bollati Boringhieri, 1998.

AGAMBEN, G. L'aperto: l'uomo e l'animale. Torino: Bollati Boringhieri, 2002.

AGAMBEN, G. La potenza del pensiero: saggi e conferenze. Vicenza: Neri Pozza, 2010.

ALVES NETO, R. R. Alienações do mundo: uma interpretação da obra de Hannah Arendt. Rio de Janeiro: PUC-Rio; São Paulo: Loyola, 2009.

ARENDT, H. Origens do totalitarismo. Tradução de Roberto Raposo. São Paulo: Companhia das Letras, 1989.

ARENDT, H. A condição humana. Tradução de Roberto Raposo. Rio de Janeiro: Forense Universitária, 2004.

ARENDT, H. Sobre a violência. Tradução de André Duarte. Rio de Janeiro: Relume-Dumará, 2011.

DURAND, G. Introdução geral à bioética: história, conceitos e instrumentos. Tradução de Nicolás Nyimi Campanário. São Paulo: Centro Universitário São Camilo; Loyola, 2012.

GIACOIA Jr., O. Sobre direitos humanos na era da biopolítica. Kriterion, v. 49, n. 118, p. 267-308, 2008.

HOBSBAWM, E. Sobre história: ensaios. Tradução de Cid Knipel Moreira. São Paulo: Companhia das Letras, 1998.

LAFER, C. A reconstrução dos direitos humanos: a contribuição de Hannah Arendt. Estudos Avançados, v. 11, n. 30, p. 55-65, 1997.

NASCIMENTO, D. A. Do fim da experiência ao fim do jurídico: percurso de Giorgio Agamben. São Paulo: LiberArs, 2012.

RUIZ, C. M. M. B. Os direitos humanos como direitos do outro. In: FERREIRA, L. F. G.; ZENAIDE, M. N. T.; PEQUENO, M. (Org.). Direitos humanos na Educação Superior: subsídios para a educação em direitos humanos na filosofia. João Pessoa: Ed. da UFPB, 2010. p. 189-228. 
NASCIMENTO, D. A.

TELES, E. L. A. Memória e verdade: a ação do passado no presente. In: FERREIRA, L. F. G.; ZENAIDE, M. N. T.; PEQUENO, M. (Org.). Direitos humanos na Educação Superior: subsídios para a educação em direitos humanos na filosofia. João Pessoa: Ed. da UFPB, 2010. p. 285-310.

Recebido: 10/06/2013

Received: 06/10/2013

Aprovado: $26 / 06 / 2013$

Approved: 06/26/2013

Rev. Filos., Aurora, Curitiba, v. 25, n. 37, p. 131-150, jul./dez. 2013 